\title{
A Case Report of Scrotal Carcinoma and Review of the Literature
}

\author{
Wei Peng ${ }^{a} \quad G^{2}$ osheng Feng ${ }^{a} \quad$ Heming $L^{b}$ Jiaxin Chen ${ }^{b}$ \\ Kehe Chen $^{\mathrm{a}}$ Yanrong Hao $^{\mathrm{b}}$ Yuhua Cao ${ }^{\mathrm{a}}$ \\ Departments of ${ }^{a}$ Medical Oncology, and ${ }^{b}$ Radiation Oncology, People's Hospital \\ of Guangxi Zhuang Autonomous Region, Nanning City, PR China
}

\section{Key Words}

Scrotal carcinoma $\cdot$ Radiation therapy $\cdot$ Lymph node metastasis

\begin{abstract}
Scrotal carcinoma is a rare tumor. We report one case of such disease in a 60-year-old man presenting with an ulcerated-bleeding lesion on the left side of the scrotum and an enlarged lymph node in the left inguinal region. Biopsy of the ulcerated lesion found squamous cell carcinoma of the scrotum. He underwent initial tumor resection and left inguinal lymph node biopsy followed by postoperative concurrent chemoradiotherapy. Postoperative pathological examination confirmed well-differentiated squamous cell carcinoma of the scrotum and lymph node metastasis. Five months after the treatment, the size of the lymph node was dramatically decreased, with no signs of tumor progression. Surgical treatment combined with concurrent chemoradiotherapy may be an appropriate management approach to achieve palliative symptom relief for this disease.
\end{abstract}

\section{Introduction}

The incidence of scrotal malignancies is extremely low [1]. The published reports usually come from small, single-institution series [2-5]. Among the primary scrotal cancers, the most common histologic type is squamous cell carcinoma. The overall survival (OS) rate is worse in patients with squamous histologic subtype, compared with other subtypes of scrotal cancer [6]. Typically scrotum carcinoma occurred in the sixth decade of life, presenting with a visible skin lesion, slow-growing and painless nodule [7]. Only $25 \%$ of inguinal nodes at presentation are metastatic. In terms of treatment modalities, wide local excision of the primary lesion with a $2-\mathrm{cm}$ clearance margin is the primary treatment option. The role of lymphadenectomy still remains unanswered. In this article, we report a case of a 60-year-old patient with scrotal 
carcinoma who achieved palliative tumor control and symptom relief after surgical treatment followed by postoperative concurrent chemoradiotherapy.

\section{Case Report}

A 60-year-old man presented at our inpatient department on October 27, 2011, with a 20-month history of an ulcerated lesion on the left side of the scrotum. Prior to admission, he was previously treated with antibiotics in private clinics, but the ulcer was uncontrolled and even deteriorated with drainage, small amount of bleeding and pain. Biopsy of the ulcerated lesion found squamous cell carcinoma of the scrotum. He had a history of nonmarital sex and no history of sexually transmitted disease or trauma in the scrotal area. He had no history of previous radiotherapy (RT) or exposure to chemicals.

Physical examination found an oval-shaped, ulcerated-bleeding lesion on the left side of the scrotum, measuring $5 \times 3 \mathrm{~cm}$ in size, and $2-3 \mathrm{~mm}$ in depth. An unmovable, mild tenderness, and enlarged lymph node was found in the left inguina, with a size of $4 \times 3 \mathrm{~cm}$. Magnetic resonance imaging (MRI) of abdomen and pelvic cavity showed abnormal changes of bilateral scrotum and multiple enlarged lymph nodes in the left inguinal region (fig. 1).

The patient underwent local excision of the skin lesion with a 2-cm margin of normal tissue and incomplete resection of enlarged lymph nodes in left inguina. The tumor at scrotum was not infiltrative into or adhesive to the testis. But the lymph nodes were adhesive to the surrounding tissues. Pathological analysis of the surgical specimen confirmed the diagnosis, showing welldifferentiated squamous cell carcinoma of the scrotum and lymph node metastasis (fig. 2 ). The patient received RT at left inguinal region, but not at scrotum, to preserve sexual function after operation. A total dose of $60 \mathrm{~Gy}$ in 33 fractions was given within a 6.5-week period. Concurrent chemotherapy with cisplatin $\left(30 \mathrm{mg} / \mathrm{m}^{2} /\right.$ week) was administered during RT course.

After the treatment was completed, the lymph nodes of left inguinal region were less adhesive to the surrounding tissues without tenderness. Five months after the treatment, the size of the lymph node was dramatically decreased, remaining $1 \mathrm{~cm}$ in diameter, with no signs of tumor progression.

\section{Discussion}

Scrotal carcinoma is a rare tumor with an overall annual incidence of approximately 1.5 per $1,000,000$ persons in Western countries [8]. Wright et al [6] collected 471 cases of scrotal cancer from 1973 to 2002 and found the most common histologic types were squamous cell carcinoma (32\%), extramammary Paget's disease (21\%), basal cell carcinoma (18\%), and sarcoma (18\%). Squamous cell carcinoma was more common in black men than in white men (69 vs. $31 \%$ ).

Scrotal carcinoma was the first malignancy linked to occupational exposure. Previous studies have found it was most commonly associated with exposure to environmental carcinogens such as chimney soot, tars, paraffin, and some petroleum products. Currently most cases result from poor hygiene and chronic inflammation [9]. The patient we report here had a 20-month chronic inflammation at scrotum, suggesting the chronic inflammation may contribute to the onset of this disease.

In general, survival was worse in patients with squamous histologic features, compared with other histologic subtypes. Johnson et al. [10] analyzed 766 patients with scrotal cancer and found median OS by histologies was 143 months for basal cell carcinoma, 165 months for extramammary Paget's disease, 180 months for sarcoma, 136 months for melanoma, 115 months for squamous cell carcinoma, and 114 months 
for adnexal skin tumor. Patients with low-risk scrotal cancer experienced a median OS of 166 months, while patients with high-risk scrotal cancer experienced a median OS of 118 months.

The primary treatment modality for scrotal carcinoma is surgery. Dai et al. [11] reported on 10 patients with scrotal carcinoma. All patients were treated with wide surgical excision without adjuvant therapy. After an average follow-up of 47 months, 8 patients were in good health without any relapse. One patient developed left inguinal lymph node metastasis at 21 months that was successfully treated with bilateral inguinal lymphadenectomy. One patient developed bilateral pulmonary metastasis at 48 months and was palliatively treated with chemotherapy.

The neoadjuvant therapy (both chemo- and radiotherapy) has also been recommended to downstage (reduction of the tumor size and lymph node status, thus improving the stage of the disease) a very large lesion in order to achieve complete resection $[12,13]$. Adjuvant RT in combination with chemotherapy (Methotrexate, Bleomycin and Cisplatinum) for four cycles is also recommended to achieve a better disease-free survival [14]. The prognosis in squamous cell carcinomas depends on various factors like age of the patient, size, grade and stage of the tumor, and the extent of surgery.

It has been reported that the status of surgical margin is an important predictor for local and/or regional tumor control. In scrotal carcinoma, it has been reported that the surgical margin is still positive despite wide excision with a 2-cm margin [15]. Thus, to minimize disease recurrence rate, it is important to ensure a negative margin has been achieved during surgical resection, In our case, the surgical margin of scrotum was negative but inguinal lymphadenectomy was incomplete. In this setting, postoperative concurrent chemoradiotherapy was important and necessary.

In summary, for a patient with scrotum carcinoma and inguinal lymph node metastasis, surgical treatment followed by adjuvant chemoradiotherapy may achieve palliative tumor control and symptom relief. However, close follow-up is warranted to evaluate long-term treatment outcomes.

\section{Disclosure Statement}

There are no actual or potential conflicts of interest of the authors. 


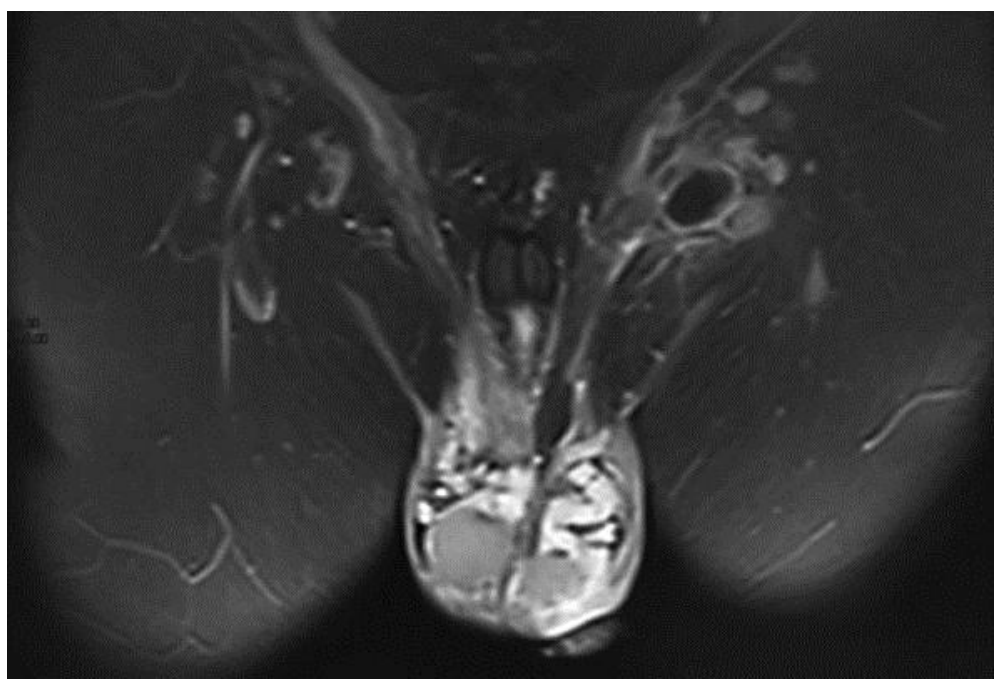

Fig. 1. MRI of abdomen and pelvic cavity showing abnormal changes of bilateral scrotum and multiple enlarged lymph nodes in the left inguinal region.

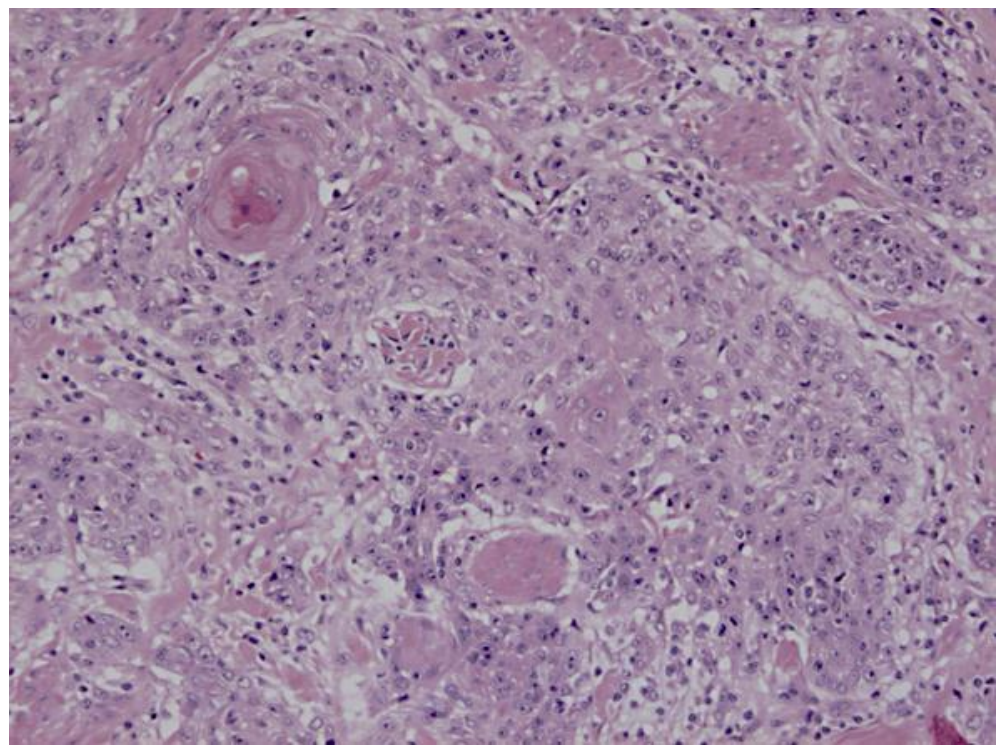

Fig. 2. Photomicrography of pathologic specimen revealing well-differentiated squamous cell carcinoma of the scrotum $(\mathrm{H} \& \mathrm{E}, \times 10)$. 


\section{References}

1 Chamorro JC, García SG, de Blas Gómez V: Scrotal carcinoma. Arch Esp Urol 2011;64:541-543.

2 Maricić A, Katunarić M, Sutalo N, Tomic S, Jurisic D, Petkovic M, Zamolo G: Primary large-cell neuroendocrine carcinoma of the scrotum. Wien Klin Wochenschr 2010;122:360-362.

3 Azike JE, Chukwujama NO, Oguike TC: Squamous cell carcinoma of the scrotum in a Nigerian: case report. Rare Tumors 2009;1:e2:4-5.

4 Chintamani, Shankar M, Singhal V, Singh JP, Bansal A, Saxena S: Squamous cell carcinoma developing in the scar of Fournier's gangrene - case report. BMC Cancer 2004;4:16.

5 Wang JW, Man LB, He F, Huang GL, Li GZ, Wang HD: Images for diagnosis. Basal cell carcinoma of the scrotum: report of a case and review of the literature. Chin Med J 2010;123:2748-2749.

6 Wright JL, Morgan TM, Lin DW: Primary scrotal cancer: disease characteristics and increasing incidence. Urology 2008;72:1139-1143.

$\checkmark 7$ Andrews PE, Farrow GM, Oesterling JE: Squamous cell carcinoma of scrotum: long-term followup of 14 patients. J Urol 1991;146:1299-1304.

8 Verhoeven RH, Louwman WJ, Koldewijn EL, Demeyere TBJ, Coebergh JWW: Scrotal cancer: incidence, survival and second primary tumours in the Netherlands since 1989. Br J Cancer 2010;103:1462-1466.

9 Presti JC Jr: Genital tumors; in Tanagho EA, McAnich JW (eds): Smith's General Urology. New York, Mc Graw Hill, 2008, pp 375-387.

10 Johnson TV, Hsiao W, Delman KA, Canter DJ, Master VA: Scrotal cancer survival is influenced by histology: a SEER study. World J Urol 2012, DOI: 10.1007/s00345-012-0834-0.

11 Dai B, Kong YY, Ye DW, Xu XW, Yao XD, Zhang SL: Basal Cell Carcinoma of the Scrotum: Clinicopathologic Analysis of 10 Cases. Dermatol Surg 2012;38:783-790.

12 Friedman R, Hanson S, Goldberg LH: Squamous cell carcinoma arising in a Leishmania scar. Dermatol Surg 2003;29:1148-1149.

13 Harder Y, Erni D, Banic A: Squamous cell carcinoma of the penile skin in a neovagina 20 years after maleto-female reassignment. Br J Plast Surg 2002;55:449-451.

14 Arai Y, Kinouchi T, Kuroda M, Usami M, Kotake T: A case of scrotal cancer with inguinal lymph node metastasis treated by multidisciplinary modalities including chemotherapy with methotrexate, bleomycin and cisplatin. Hinyokika Kiyo 1997;43:683-685.

15 Ng LG, Yip SK, Tan PH: Extramammary Paget's disease of scrotum. Urology 2001;58:105. 